\title{
The impact of shared domain knowledge on strategic information systems planning and alignment
}

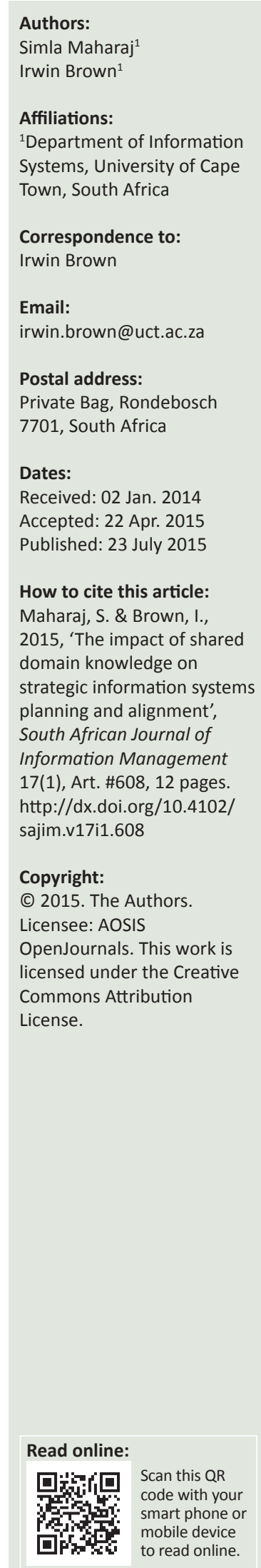

Background: Lack of alignment or harmony between information technology (IT) and business imperatives continues to plague organisations despite decades of research. Strategic information systems planning (SISP) is the process of coordinating the relationship between IT and the business in order to steer alignment. Shared domain knowledge (SDK) is a factor that is posited as important for improving both SISP and alignment, which is theorised to be the main outcome of SISP.

Objectives: The aim of this article is to examine the impact of SDK on SISP and alignment.

Method: Data were gathered from management consultants in a large, global IT organisation, through the use of a structured questionnaire, and analysed.

Results: It was shown that SDK positively influences SISP characteristics and the alignment outcome. Specifically, it was found that high levels of rationality in SISP positively influenced the intellectual dimension of alignment, whilst IT manager participation in business planning influenced the social dimension of alignment. SDK was found to have a bearing on all of the SISP characteristics measured (i.e. rationality, adaptation, business planning-SISP integration and IT manager participation in business planning). SDK was also found to positively impact both the intellectual and social dimensions of alignment.

Conclusion: The implications of the findings are that fostering a knowledge sharing environment in organisations will help improve alignment, as well as the formal processes designed to steer alignment such as SISP.

\section{Introduction}

Strategic information systems planning (SISP) has been established as a core activity in the governance and management of information technology (IT) in organisations (Bechor et al. 2010; Hayward 2013). SISP is carried out in organisations primarily as a means to improve the level of alignment between IT and business strategies and objectives (Karanja \& Patel 2012). Both SISP and business-IT alignment have been consistently ranked as key issues amongst IT managers globally, which highlights the importance of research into these phenomena (Luftman et al. 2013). SISP can be seen as the process by which alignment is achieved and is variously referred to as information systems strategic planning (ISSP), information systems (IS) strategy development or formation (i.e. formulation and implementation) and IS strategising (Peppard, Galliers \& Thorogood 2014). Business-IT alignment has been theorised to be a key outcome of SISP (Lederer \& Salmela 1996; Osman, El Beltagi \& Hardaker 2013; Yang, Pita \& Singh 2014). Business-IT alignment, when viewed as an outcome of SISP, is defined as the state in which IT and business plans and strategies are coherently interrelated, as well as the degree to which there is congruence of vision between business and IT executives on business and IT strategy (Reich \& Benbasat 2000; Silvius 2013).

Shared domain knowledge (SDK) between business and IT executives is known to enhance efficiency and effectiveness of strategic IT management processes such as SISP (Ranganathan \& Sethi 2002). There is evidence too that SDK has a direct impact on business-IT alignment, that is, there is not only an indirect impact through SISP (Preston \& Karahanna 2009). The purpose of this research is hence to interrogate the various direct and indirect relationships between SDK, SISP and business-IT alignment in order to gain a better understanding of the dynamics between these important factors (Leonard \& Seddon 2012). The research question posed is: What is the impact of shared domain knowledge on strategic information systems planning and its effectiveness, as measured by alignment?

In the next section the key concepts underpinning the study will be elucidated, after which the research model is established. The methodology by which data were collected and analysed 
is then outlined after which the results are presented. Discussion and implications of the results follow, then the article is concluded.

\section{Conceptual background}

Shared domain knowledge, strategic information systems planning characteristics and business-IT alignment and their interrelationships are the focus of attention in this study, so each will be discussed logically in turn.

\section{Shared domain knowledge (SDK)}

SDK is defined as the ability of IT and business executives to mutually understand the key processes in the domains of business and IT respectively and to be able to mutually contribute and participate meaningfully in the activities of each domain (Chan, Sabherwal \& Thatcher 2006). Related concepts that have received attention in literature include shared knowledge and knowledge sharing (Kearns \& Lederer 2003; Pai 2005; Preston \& Karahanna 2009; Reich \& Benbasat 2000). Shared knowledge is described as 'an understanding and appreciation among IT and line managers for the technologies and processes that affect their mutual performance' (Reich \& Benbasat 2000), whilst Pai (2005) describes knowledge sharing as 'a set of behaviours that involve the exchange of information or assistance to others'. Implicit in our definition of SDK are the elements of shared knowledge and knowledge sharing; hence, literature related to the latter two concepts has relevance to discussions of SDK too (Preston \& Karahanna 2009). A strong environment and culture of knowledge sharing is argued to be conducive to effective strategising (Teubner 2013). Kearns and Lederer (2003) examined how knowledge sharing (represented by the transfer of knowledge between CIO and CEO) assists in generating competitive advantage. SDK and knowledge sharing have been shown to be key considerations in achieving alignment between business and IT objectives (Chan et al. 2006; Pai 2005; Preston \& Karahanna 2009; Reich \& Benbasat 2000; Tan \& Gallupe 2006). Ranganathan and Sethi (2002) examined the impact of SDK on rationality in strategic IT decisions and found a strong and positive influence. Whilst issues such as competitive advantage, alignment and rationality in decision-making are associated with SISP, there have been few studies that explicitly link SDK to SISP; hence, there still remains a research gap on how these phenomena interrelate. The next section discusses key characteristics associated with SISP.

\section{Strategic information systems planning (SISP) and its characteristics}

Improving SISP has persisted as a key issue for IT executives for several decades now (Luftman et al. 2013); hence, research on this phenomenon remains relevant to pursue. SISP is defined as a strategic endeavour that involves identification of a prioritised portfolio of IT applications for an enterprise, together with the necessary infrastructure, resources, organisational structure and change management considerations necessary for implementation (Baker 1995 as cited by Brown 2004; Teubner 2013). This definition for SISP has persisted for over two decades, which demonstrates that SISP is an enduring activity for IT management in a dynamic and rapidly evolving field.

Whilst there are a large number of methodologies to choose from when carrying out SISP, common to most are several key phases and activities. These methodology-independent phases include strategic awareness (preparing for the SISP process), situational analysis (analysing the external and internal business and IS environment), strategy conception (conceiving and evaluating alternative scenarios), strategy formulation (selecting a strategy) and implementation planning (Mirchandani \& Lederer 2014; Newkirk \& Lederer 2006).

It has been found that success of SISP varies depending on the characteristics of the SISP approach being used in an organisation (Grover \& Segars 2005; Osman et al. 2013; Silvius \& Stoop 2013). Key SISP characteristics include the levels of rationality, adaptation and integration with business planning (Segars \& Grover 1999; Teo \& King 1997). SISP approaches exhibiting high levels of rationality, adaptation and integration have been found to be the most successful, especially in the context of a volatile environment (Grovers \& Segars 2005). The typical measure of SISP success is the extent of business-IT alignment achieved (Sylvius 2013).

Rationality in SISP is recognised by comprehensiveness in decision-making, a top-down flow of decision-making, a focus on control and a high degree of formalisation (Chen et al. 2010; Segars \& Grover 1999). Adaptation is evidenced by frequent meetings to consider and revise plans and broad participation of stakeholders (Segars \& Grover 1999). Business planning-IS planning (BP-ISP) integration varies from having no integration at one extreme to a fully integrated process at the other extreme. Table 1 provides detailed definitions of these elements.

An aspect that is related to BP-ISP integration, but deserves separate consideration in the context of SISP is the level of IT manager participation in business planning (Kearns \& Lederer 2003). Whilst organisations may have mechanisms and structures for BP-ISP integration, the level of IT manager participation in business planning may still vary. For example, an IT manager may be present at business planning sessions, but if not fully part of the proceedings, and if their voice is not taken in to account, then participation and involvement of IT managers will still be low (Cordoba 2009).

\section{Strategic information systems planning (SISP) effectiveness - Alignment}

SISP effectiveness has been defined as the extent to which key planning objectives have been fulfilled (Premkumar \& King 1994). Key objectives of SISP include alignment between business and IT objectives, analysis of the business and IT environment, improved cooperation between stakeholders to ensure plan implementation and 
TABLE 1: Strategic information systems planning process - Characteristics.

\begin{tabular}{|c|c|}
\hline Characteristic & Definition \\
\hline Comprehensiveness & The extent to which an organisation attempts to be exhaustive or inclusive in making and integrating decisions \\
\hline Flow & The locus of authority or devolution of responsibilities for strategic planning (top-down, bottom-up, interactive) \\
\hline Focus & The balance between creativity and control orientations inherent within the strategic planning system \\
\hline Formalisation & The existence of structures, techniques, written procedures and policies that guide the planning process \\
\hline Frequency & $\begin{array}{l}\text { The frequency of planning activities or cycles and, relatedly, the frequency of evaluation and revision of strategic choices } \\
\text { (occasional vs continuous) }\end{array}$ \\
\hline Participation & The breadth of involvement in strategic planning (narrow vs wide) \\
\hline BP-ISP integration & $\begin{array}{l}\text { The level of integration between business planning and SISP (business-led, IT-led, reciprocal, full integration or proactive) } \\
\text { (Reich \& Benbasat 2000; Teo \& King 1997) }\end{array}$ \\
\hline IT manager participation in business planning & IT manager attendance, participation and involvement in business planning (Kearns \& Sabherwal 2007) \\
\hline
\end{tabular}

improvements in organisational capability to carry out SISP (Segars \& Grover 1999; Yang et al. 2014). From amongst these objectives, alignment has been persistently noted as the key objective of SISP (Chen et al. 2010; Karanja \& Patel 2012; Silvius 2013).

The concept of alignment is broad and multi-faceted (Chan $\&$ Reich 2007). Alignment can be viewed as a process or an outcome (Karpovsky \& Galliers 2015). The perspective adopted in this study is that it is the outcome of SISP. When viewed as an outcome of SISP, key dimensions of alignment have been identified as the intellectual and social dimension (Reich \& Benbasat 2000). The intellectual dimension is defined as the state in which a set of highquality interrelated business plans and IT plans exist (Reich \& Benbasat 1996). The social dimension refers to the state in which IT and business executives understand and are committed to the business and IT mission, objectives and plans (Reich \& Benbasat 2000). Reich and Benbasat (2000) further distinguish between short-term social alignment the degree of mutual understanding between business and IT executives of business and IT objectives - and longterm alignment - the congruence of shared vision between business and IT executives. Few studies have considered both the intellectual and social dimensions in one study, due to a lack of conceptual clarity around these dimensions and their measurement (Chan \& Reich 2007; Schlosser, Wagner \& Coltman 2012)

\section{Hypothesis development}

Drawing from the literature on SDK, SISP and alignment, a set of hypotheses to be tested were derived. These will be discussed in turn.

\section{BP-ISP integration and alignment}

Reich and Benbasat (2000) demonstrated a positive relationship between BP-ISP integration and the social dimension of alignment. BP-ISP integration is also expected to have an impact on the intellectual dimension of alignment. For example Brown (2004) suggests that greater BP-ISP integration yields a more useful and comprehensive IS plan, signalling high levels of intellectual alignment. Hence the following hypotheses are supported:
H1: BP-ISP integration positively influences the social dimension of alignment

H2: BP-ISP integration positively influences the intellectual dimension of alignment

\section{SISP rational-adaptation and alignment}

Grover and Segars (2005) demonstrate that a process characterised by high levels of both rationality and adaptation is associated with successful SISP. Success was measured in their study by assessing, amongst other elements, alignment. The measure of alignment they used included items relating to both the intellectual and social dimensions, hence supporting the following hypotheses:

H3: Rationality in SISP positively influences the social dimension of alignment

H4: Rationality in SISP positively influences the intellectual dimension of alignment

H5: Adaptation in SISP positively influences the social dimension of alignment

H6: Adaptation in SISP positively influences the intellectual dimension of alignment

\section{IT manager participation in business planning and alignment}

IT manager participation in business planning has been shown to lead to positive outcomes such as achieving alignment (Chi et al. 2005; Kearns \& Lederer 2003; Kearns \& Sabherwal 2007). There needs to be caution against paying lip service to the concept of participation (Cordoba 2009), for example inviting the IT manager to be part of business planning activities, but not taking on board their suggestions and input:

H7: IT manager participation in business planning positively influences the social dimension of alignment

H8: IT manager participation in business planning positively influences the intellectual dimension of alignment

\section{Shared domain knowledge and SISP characteristics}

The benefits of SDK for IT strategic management have been well reported. Ranganathan and Sethi (2002) demonstrate 
its positive impact on rationality in strategic IT decisionmaking. Rationality was operationalised by dimensions of comprehensiveness and formalisation, attributes noticeable in a rational SISP process (Segars \& Grover 1999). SDK has been associated with IT manager participation in business planning and business manager participation in SISP (Kearns \& Sabherwal 2007; Reich \& Benbasat 2000); a characteristic of SISP adaptation is business participation in SISP (Grover $\&$ Segars 2005). SDK has also been associated with BP-ISP integration (Kearns \& Sabherwal 2007; Reich \& Benbasat 2000). Hence, the following hypotheses are supported:

H9: Shared domain knowledge positively influences rationality in SISP

H10: Shared domain knowledge positively influences adaptation in SISP

H11: Shared domain knowledge positively influences BP-ISP integration

H12: Shared domain knowledge positively influences IT manager participation in business planning

\section{Shared domain knowledge and alignment}

A lack of shared knowledge between business and IT is argued to be one of the key challenges to achieving alignment (Chan \& Reich 2007). Chan et al. (2006) demonstrate the effect of SDK on the intellectual dimension of alignment, whilst Reich and Benbasat (2000) and Preston and Karahanna (2009) demonstrate this impact on the social dimension of alignment in the long term and short term respectively. Hypotheses supported are:

H13: Shared domain knowledge positively influences the social dimension of alignment

H14: Shared domain knowledge positively influences the intellectual dimension of alignment

The conceptual model illustrating these 14 hypotheses is illustrated in Figure 1.

\section{Research methodology}

The research methodology followed a positivist, quantitative, hypothetico-deductive approach. Further details on the research instrument, the data collection process and the data analysis procedure are provided in this section.

\section{Development of the measures for research constructs}

The measures used in this study were based on validated instruments from relevant studies (Cohen \& Toleman 2006; Kearns \& Lederer 2003; Kearns \& Sabherwal 2007; Ranganathan \& Sethi 2002; Reich \& Benbasat 2000; Segars \& Grover 1999; Teo \& King 1997). These measures and their sources are illustrated in Appendix 1. A seven-point Likert scale ranging from 1 for 'strongly disagree' to 7 for 'strongly agree' was employed in the questionnaire for all items except BP-ISP integration, which employed a typology of integration modes as per Teo and King (1997).

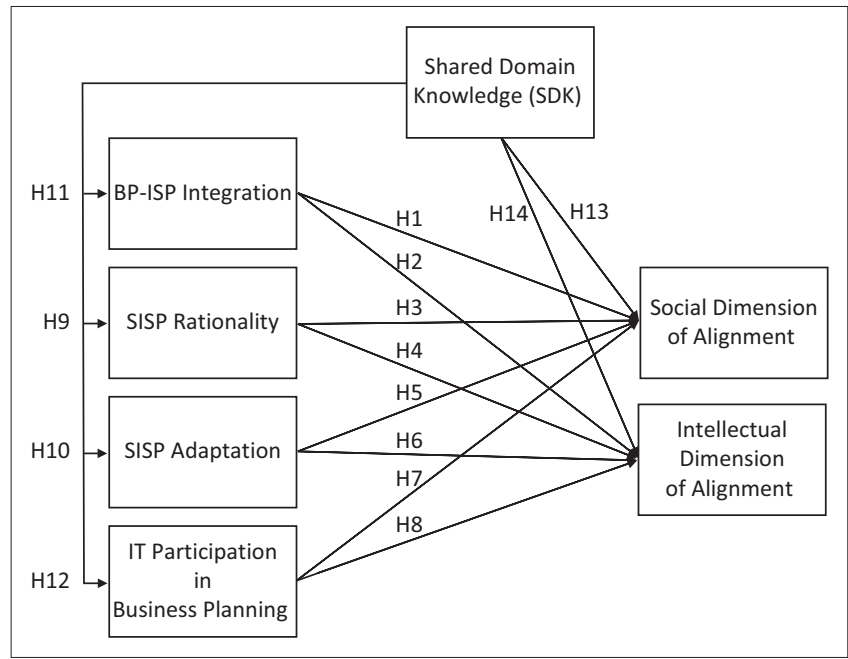

FIGURE 1: Conceptual model.

SDK was measured using the Ranganathan and Sethi (2002) instrument supplemented by measures from Kearns and Sabherwal (2007). SISP rationality was operationalised in this study by the dimensions of comprehensiveness and formalisation as in Ranganathan and Sethi (2002). The measurement scales for comprehensiveness and formalisation were adapted from instruments developed by Segars and Grover (1999). For the higher order characteristic of SISP adaptation, dimensions of participation and frequency were used, again using measures developed by Segars and Grover (1999). IT manager participation in business planning was measured with the instrument developed by Kearns and Sabherwal (2007).

For BP-ISP integration the measure by Teo and King (1997) was used, which provided a typology of integration varying from administrative (little or no integration) to sequential (SISP follows business planning) to reciprocal (SISP and business planning are mutually interacting) to full integration (no separate SISP and business planning). Reich and Benbasat (2000) also identified proactive integration (SISP precedes business planning) as a type of integration, so this mode was also added to the measure. Respondents were asked to select which description most closely fitted the BP-ISP integration level in the organisation they were involved with.

The research questions used for measuring the social dimension of alignment construct were adapted from an instrument from a study by Cohen and Toleman (2006). This instrument included both short-term and longterm alignment measures. For measuring the intellectual dimension of alignment measures were adapted from an instrument by Kearns and Lederer (2003).

\section{Data collection}

\section{Sampling}

The target population for this study consisted of consultants from a large, global IT organisation who were based at companies that had conducted SISP in the last 10 years. These consultants had participated in SISP at the specific company 
in which they were based. Most studies in SISP rely on the views of the IT executive to represent the organisation, whilst a few also include the business executive. The views of external consultants are not often represented in SISP research. The advantage of obtaining a consultant perspective is that it may offer a perhaps less biased view of SISP in organisations than that of IT or business executives. Random sampling was used so that each population member had an equal chance of being selected. Three-hundred consultants from the large global IT organisation were asked to respond to the questionnaire.

\section{Pilot testing}

The questionnaire was first pre-tested by three academics with experience in this area of research. Wording of questions (such as tenses) was amended as a result. A pilot test was thereafter conducted with five IT consultants, three of whom were from the large, global IT organisation with two others from other organisations. Based on the feedback, some questions were reworded and some questions were removed as the respondents felt that they were repetitive. Generally, the questionnaire was well understood with positive feedback, for example that the instructions were clear and the length of the questionnaire was adequate. The changes that were suggested in the feedback were made accordingly and the final questionnaire was posted on a website to be used for data collection.

\section{Data collection procedure}

The online questionnaire was hosted on a general survey website and all consultants in the sample were sent an email which included the link to the questionnaire. Confidentiality of responses was assured and respondents were asked to provide their contact details in the survey if they wished to receive a copy of the findings of this study. Email reminders were sent every two weeks for one month to ensure that the maximum number of consultants answered the questionnaire. The responses to the questionnaire were saved to the website's database and downloads of the responses were available at all times.

\section{Response rate}

Three-hundred consultants from one large, global IT organisation were targeted for this survey and on closure of the online survey, a total of 175 consultants had responded to the survey. On analysis of the responses, it was found that 59 questionnaires were answered completely, representing a $19.7 \%$ response rate. Although low, this was deemed an acceptable response rate for this type of survey, as it is widely acknowledged that surveys targeting senior level managers and professionals suffer from low response rates. Other SISP survey-based studies have had similar response rates (e.g. Cohen 2008; Mirchandani \& Lederer 2014).

\section{Data analysis procedure}

The first part of the data analysis process was to conduct basic descriptive statistics on the questionnaire responses.
Frequency tables based on the demographic data in the responses were developed. The next part of the data analysis was the execution of a factor analysis exercise to validate the items and to identify if there were any structures in the relationships between items. The Cronbach's alpha coefficient for the final set of research items was thereafter applied to test reliability. Finally the hypotheses developed in this study were tested using multiple linear regression.

\section{Data analysis and results Demographic profile}

The demographic profile of the respondents is illustrated in the tables below. Table 2 reveals that $72 \%$ of the sample had senior executive experience and $74 \%$ had more than 10 years of IS experience. Approximately $90 \%$ of the respondents had up to 15 years of SISP experience with about $9 \%$ of the respondents having more than 15 years of SISP experience.

Diverse industries were represented in the sample. Manufacturing and finance had the most responses about $32 \%$ and $31 \%$ of the sample respectively (Table 3 ). The transport, engineering, service, government, retail, communications and IT industries had less than $10 \%$ responses each, but together they accounted for about 35\% of the responses. Other descriptive data revealed that most organisations were large in terms of annual revenue. About

\begin{tabular}{lcc}
\multicolumn{2}{l}{ TABLE 2: Level of experience of respondents. } & \multicolumn{1}{l}{} \\
\hline Item & $f$ & $\%$ \\
\hline Level of management experience & 5 & 8.6 \\
Junior & 10 & 17.2 \\
Middle & 42 & 72.4 \\
Senior & & \\
Number of years of IS experience & 7 & 12.1 \\
$<5$ & 7 & 12.1 \\
$5-10$ & 17 & 29.3 \\
$10-15$ & 15 & 25.9 \\
$15-20$ & 11 & 19.0 \\
$>20$ & & \\
Number of years of SISP experience & 20 & 34.5 \\
$<5$ & 25 & 43.1 \\
$5-10$ & 7 & 12.1 \\
$10-15$ & 4 & 6.9 \\
$15-20$ & 1 & 1.7 \\
$>20$ & & \\
\hline
\end{tabular}

TABLE 3: Industry in which SISP was conducted.

\begin{tabular}{lcc}
\hline Industry & $\boldsymbol{f}$ & $\mathbf{\%}$ \\
\hline Manufacturing & 19 & 32.8 \\
Communications & 5 & 8.6 \\
Finance & 18 & 31.0 \\
Retail & 1 & 1.7 \\
IT & 3 & 5.2 \\
Government & 4 & 6.9 \\
Transport & 3 & 5.2 \\
Engineering & 1 & 1.7 \\
Service & 3 & 5.2 \\
\hline
\end{tabular}

$f$, frequency 
$38 \%$ had revenues in excess of USD 500 million and only $9 \%$ had revenues of less than USD 5 million.

\section{Construct and discriminant validity}

The questionnaire was derived from previously validated instruments, so confirmatory factor analysis (CFA) was used to assess construct and discriminant validity (Tan \& Teo 2000). Commonly applied decision rules were used, including using a minimum eigenvalue of 1 as a cut-off value for extraction, deleting items with factor loadings of less than 0.5 on all factors, or greater than 0.5 on two or more factors, using varimax rotation and so on (Tan \& Teo 2000). Through progressive refinement, a set of validated constructs emerged.

Appendix 2 shows the factor loadings achieved after elimination of items. SDK loaded on two factors - one related to business knowledge of IS (SDK_BUS) and the other related to IS knowledge of business (SDK_IS). Together these two sub-factors made up SDK. Also loading as distinct factors were SISP rationality (RATIONAL) and SISP adaptation (ADAPT). It was expected that rationality would have two sub-factors - comprehensiveness and formalisation - but these two loaded together as a single factor of rationality (RATIONAL), which was nevertheless consistent with their common underlying meaning. Adaptation too was expected to have two factors - participation and frequency - but once again it loaded as a single factor (ADAPT), which was again consistent with the commonality in meaning. IT manager participation in business planning (ISBP) loaded as a separate factor, as expected.

Amongst the alignment factors two major dimensions were expected - the social dimension of alignment and intellectual dimension of alignment. The social dimension had two separate sub-factors - long-term alignment (SOC_ LT ALIGN) and short-term alignment (SOC_STALIGN). The intellectual dimension of alignment also had two sub-factors IS plan-business plan alignment (INT_ISPBPALIGN) and business plan-IS plan alignment (INT_BPISPALIGN). The refined constructs thus exhibited adequate construct and discriminant validity.

\section{Instrument reliability}

In order to assess reliability of the refined instrument, the Cronbach's alpha was calculated for each construct (Tan \& Teo 2000). Reliability is indicated if the Cronbach's alpha is greater than 0.7. The lowest Cronbach's alpha was 0.76, thus demonstrating that all measures exhibited reliability (see Appendix 2).

\section{Items means and standard deviations}

Table 4 shows that the mean for SDK is close to 5 , which reveals that respondents on average agreed that IT and business executives had the ability to understand and were able to participate in the others' key processes and to respect
TABLE 4: Descriptive statistics.

\begin{tabular}{lll}
\hline Item & M & SD \\
\hline Shared domain knowledge (SDK) & 4.9 & 0.97 \\
SISP rationality (RATIONAL) & 4.4 & 1.13 \\
SISP adaptation (ADAPT) & 4.9 & 1.19 \\
IT manager participation business planning (ISBP) & 4.3 & 1.53 \\
Social dimension of alignment & 4.5 & 1.23 \\
Intellectual dimension of alignment & 4.5 & 1.23 \\
\hline
\end{tabular}

$\mathrm{M}$, mean; SD, standard deviation

each other's unique contribution and challenges. The mean scores for SISP rationality (RATIONAL) and IT manager participation in business planning (ISBP) were about 4 , implying respondents were on average neutral with respect to the extent to which their organisations exhibited a high degree of rationality and participation in business planning. SISP adaptation (ADAPT), social alignment and intellectual alignment had means that were closer to 5 . This reveals that respondents on average agreed that there was a high degree of SISP adaptation. They also agreed on average that there was a state within the respective companies where business and IT executives understood and were committed to the business and IT mission, objectives and plans, and they agreed on average that there was a close linkage between the IS strategy and business strategy.

\section{BP-ISP integration types}

In terms of BP-ISP integration, just over $48 \%$ of organisations exhibited sequential integration, which means that a sequential relationship existed between business planning and SISP, with IS plans primarily focused on providing support for business plans. About 19\% of the companies exhibited administrative integration, which represents a weak relationship between business planning and SISP. About $16 \%$ of the companies exhibited reciprocal integration, representing a reciprocal and interdependent relationship between business planning and SISP, in which SISP plays a role in both supporting and influencing business plans. About $12 \%$ of the sample claimed there was full BP-ISP integration with little distinction between business planning processes and SISP processes. Only 5\% of the sample showed proactive BP-ISP integration in which IS objectives precede the formulation of business objectives and are used as input to their development. Hence, all BP-ISP integration types were present, demonstrating the diversity of the sample.

\section{Multiple linear regression}

Multiple linear regression was used to test the 14 hypotheses formulated in this study. The dependent variables against which the independent variables were regressed were the social dimension of alignment, intellectual dimension of alignment and the SISP characteristics (rationality, adaptation, BP-ISP integration and IT manager participation in business planning). The common dependent variable was SDK. The results of the multiple linear regression are illustrated in Table 5 together with the associated hypotheses. $p$-values that were less than or equal to 0.05 were considered significant. 
TABLE 5: Results of multiple linear regression.

\begin{tabular}{|c|c|c|c|c|}
\hline Dependent item & Hypothesis & Independent item & Beta & $p$-level \\
\hline \multirow[t]{5}{*}{ Social dimension of alignment } & $\mathrm{H} 1$ & BP-ISP integration & -0.04 & 0.624 \\
\hline & H3 & Rationality & 0.15 & 0.124 \\
\hline & H5 & Adaptation & 0.07 & 0.550 \\
\hline & $H 7$ & IT manager participation in business planning & 0.55 & 0.000 \\
\hline & $H 13$ & $S D K$ & 0.25 & 0.022 \\
\hline \multirow[t]{3}{*}{ Intellectual dimension of alignment } & $\mathrm{H} 2$ & BP-ISP integration & 0.05 & 0.620 \\
\hline & $\mathrm{H} 6$ & Adaptation & 0.05 & 0.726 \\
\hline & $\mathrm{H} 7$ & IT manager participation in business planning & 0.21 & 0.091 \\
\hline SISP characteristics & H14 & $S D K$ & 0.38 & 0.006 \\
\hline Rationality & $H 9$ & $S D K$ & 0.41 & 0.001 \\
\hline Adaptation & H10 & $S D K$ & 0.68 & 0.000 \\
\hline BP-ISP integration & H11 & $S D K$ & 0.52 & 0.000 \\
\hline IT manager participation in business planning & H12 & $S D K$ & 0.65 & 0.000 \\
\hline
\end{tabular}

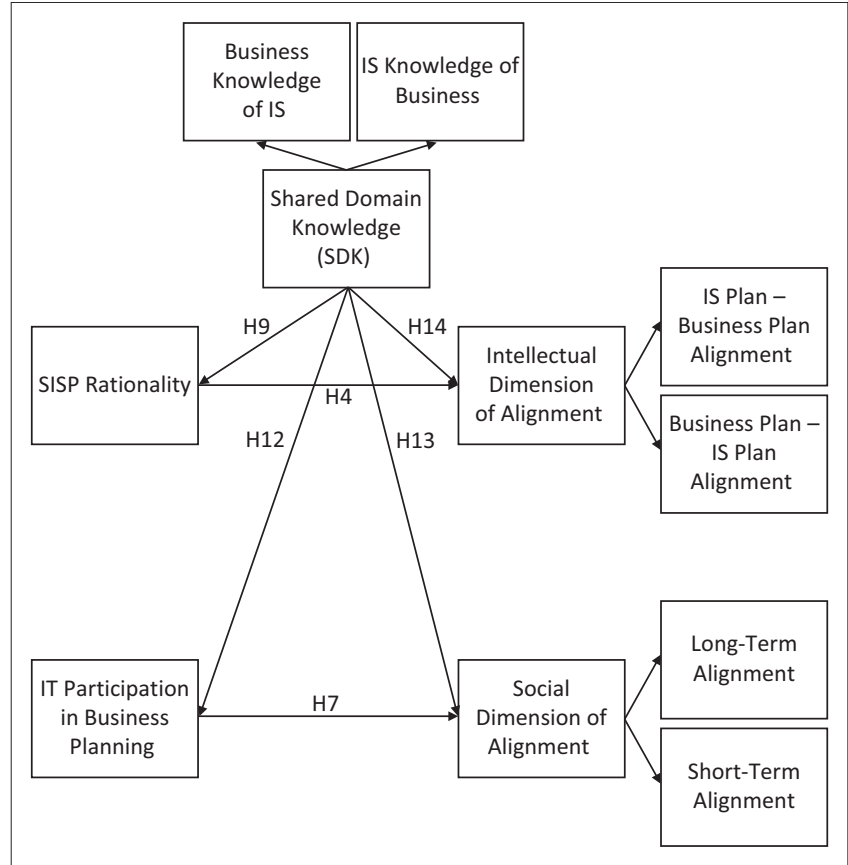

FIGURE 2: Refined conceptual model.

It was noticeable that all hypotheses concerning the impact of SDK (H9 to H14) were supported, meaning that SDK had an impact on all SISP characteristics (rationality, adaptation, BP-ISP integration and IT manager participation in business planning), as well SISP effectiveness (social dimension of alignment and intellectual dimension of alignment). In terms of the influence of SISP characteristics on alignment, the social dimension of alignment was impacted by IT manager participation in business planning only (H7) and not by rationality, adaptation or BP-ISP integration. The intellectual dimension of alignment was impacted by rationality only (H4) and not adaptation, BP-ISP integration or IT manager participation in business planning.

The results in Table 5 lead to the refined conceptual model, as shown in Figure 2. SISP adaptation and BP-ISP integration were only weakly associated with the alignment dimensions and so were removed from the model. The factor analysis revealed a two-factor structure for shared domain knowledge (business knowledge of IS and IS knowledge of business), intellectual dimension of alignment (IS plan-business plan alignment and business plan-IS plan alignment) and the social dimension of alignment (long-term and short-term alignment).

\section{Discussion and implications SISP characteristics and alignment}

The social and intellectual dimensions of alignment respectively were used as a measure of SISP effectiveness. The impact of the SISP characteristics of rationality, adaptation, BP-ISP integration and IT manager participation in business planning were tested. It was found that there was support only for IT manager participation in business planning positively influencing the social dimension of alignment. The positive influence arises because IT manager participation in business planning involves IT executives regularly attending business meetings, participating in setting business goals and objectives and being involved early in the meetings for major projects. All of these actions ultimately contribute to the social dimension of alignment: the shared vision of business and IS executives on the role of IS in the organisation and the mutual understanding of each other's domains. This finding is in keeping with the results of Kearns and Sabherwal (2006). The lack of influence of rationality, BP-ISP integration and adaptation would suggest that formalised SISP procedures, structural mechanisms for BP-ISP integration, business executive participation in SISP sessions and frequent SISP meetings are less useful for achieving social alignment. Business executives would likely not have time to attend too many SISP sessions, so a better strategy is for the IT manager to go to the business planning meetings and there make contributions for the strategic use of IT in organisations.

In terms of the influence of the aforementioned SISP characteristics on the intellectual dimension of alignment, there was only support for SISP rationality positively influencing intellectual alignment. So, a high level of comprehensiveness, formalised procedures and documentation of outputs in SISP ensures that the documented IS plan reflects the business mission and goals and supports the business strategies. In a like manner, it ensures that the business plan can refer to the 
IS plan and that it utilises the strategic capability of IS and contains reasonable expectations of IS. The lack of influence of adaptation, BP-ISP integration and IT manager participation in business planning perhaps indicates that for achieving alignment on the intellectual level, the best strategy is a highly rational SISP process that follows a formal methodology and procedure and yields a comprehensive well-documented IS plan, with links and references to business plans and strategies.

In all, these findings yield interesting insights into the role of SISP in achieving alignment and how the different characteristics affect alignment. Segars and Grover (1999) show through cluster analysis that a SISP process characterised by rationality and adaptation is associated with SISP effectiveness (alignment, analysis, cooperation and capability improvement respectively). Their study never tests the relationships between the separate SISP characteristics and the separate dimensions of SISP effectiveness. This study makes a contribution by empirically testing the relationships between specific SISP characteristics and alignment and reveals that the rationality dimension of SISP is important for intellectual alignment, whilst for social alignment, the IT manager participation in business planning might be more important than a formal SISP process.

\section{SDK and SISP characteristics}

The SISP characteristics of rationality, adaptation, BP-ISP integration and IT manager participation in business planning have been shown to be important, not only to alignment, but also to other measures of SISP effectiveness such as analysis, cooperation, capability improvement, IS function performance, IS contribution to business performance and improved business performance itself (Kearns \& Sabherwal 2007; Premkumar \& King 1994; Segars \& Grover 1999). Hence, it is important that ways of enhancing these characteristics are found. SDK was found to positively influence all of the aforementioned characteristics. Hence, improving SDK (i.e. IS knowledge of business and business knowledge of IS) provides for an important strategy for improving SISP in organisations.

\section{SDK and SISP effectiveness - Alignment}

With the overall SISP effectiveness being measured by the social dimension of alignment and the intellectual dimension of alignment, SDK was tested against both and it was found that there was support for SDK positively influencing both the social and intellectual dimensions of alignment. The findings suggest that achieving social alignment may not require a detailed formalised SISP process. Rather, through improving SDK in an organisation, a shared vision and shared understanding between business and IS executives can be achieved. Coupled with IT manager participation in business planning, which itself is strengthened by SDK, the social dimension of alignment can be strongly realised.

For achieving intellectual alignment a rational SISP process is still needed, but even in this case, SDK will be of complementary value both to improving levels of rationality and directly to improving the intellectual dimension of alignment.

\section{Summary}

In summary, the findings suggest that organisations should focus on creating a knowledge sharing environment between business and IT and seek for ways to strengthen IS knowledge of business and business knowledge of IS. In this way SISP characteristics and outcomes such as alignment will be improved.

\section{Limitations and future research}

The target population of this study consisted of consultants from one large, global IT organisation, based at various customer sites around the world, who participated or observed the SISP in the company where they were based. Even though the responses were based on various types of organisation from various industries, including responses from consultants only could be a limitation of this study. Bias could result from these consultants possibly having a deeper knowledge of IS, which could have resulted in them responding to the questionnaire from an IS perspective. A suggestion for further research could be to test the research model that was developed in this study by including various roles from business and IT in the target population. A further limitation is the small number of completed questionnaires on which the conclusions of this study were based. Even though there were 175 responses, only 59 of the 175 were complete. Future research could try to elicit a higher response rate in order to test if all the hypotheses in this study still hold true with more response data.

\section{Conclusion}

The objective of this study was to investigate the impact of SDK on SISP and its effectiveness, as measured by alignment. The research model included the examination of how SDK impacted theSISP process dimensions (rationality, adaptation, BP-ISP integration and IT manager participation in business planning), how the SISP process dimensions (rationality, adaptation, BP-ISP integration and IT manager participation in business planning) impacted SISP effectiveness (measured by social and intellectual alignment) and lastly how SDK impacted SISP effectiveness (i.e. alignment). Few, if any, studies have investigated all these facets in a single study.

On a methodological level, the study has contributed by demonstrating the validity and reliability of measures for investigating SISP characteristics, alignment and SDK, these being taken from disparate sources. The study reveals a two-factor structure for SDK (business knowledge of IS and IS knowledge of business), the intellectual dimension of alignment (IS plan-business plan alignment and vice versa) and the social dimension of alignment (long-term and short-term alignment respectively), in keeping with the conceptualisation of these constructs.

The study makes a theoretical contribution by revealing the impact of SISP on two dimensions of alignment - the social and intellectual respectively. In so doing it is shown that a formal, comprehensive rational SISP process is the key driver of the intellectual dimension of alignment, whilst the social dimension 
of alignment is more likely achievable by the IT manager participating in business planning rather than vice versa (i.e. business executives participating in SISP). Shared domain knowledge between business and IT executives positively influences both SISP and the dimensions of alignment.

These findings are of practical benefit, as three actions for organisations to implement can be garnered, these being: (1) improve rationality of SISP processes as a means to improving the intellectual dimension of alignment; (2) involve IT managers strategically in business planning to improve the social dimension of alignment; (3) establish a knowledge sharing culture and implement mechanisms to build shared domain knowledge in the organisation. Implementing these initiatives will improve both SISP and the aforementioned facets of alignment.

\section{Acknowledgements Competing interests}

The authors declare that they have no financial or personal relationships that may have inappropriately influenced them in writing this article.

\section{Authors' contributions}

S.M. (University of Cape Town) conducted the overall study whilst registered as a student at the University of Cape Town. I.B. (University of Cape Town) supervised the study and contributed to writing the article.

\section{References}

Bechor, T., Neumann, S., Zviran, M. \& Glezer, C., 2010, 'A contingency model for estimating success of strategic information systems planning', Information \& Management 47(1), 17-29. http://dx.doi.org/10.1016/j.im.2009.09.004

Brown, I.T.J., 2004, 'Testing and extending theory in strategic information systems planning through literature analysis', Information Resources Management Journal 17(4), 19-47. http://dx.doi.org/10.4018/irmj.2004100102

Chan, Y.E. \& Reich, B.H., 2007, 'IT alignment: What have we learned?', Journal of Information Technology 22(4), 297-315. http://dx.doi.org/10.1057/palgrave. jit.2000109

Chan, Y.E., Sabherwal, R. \& Thatcher, J.B., 2006, 'Antecedents and outcomes of strategic IS alignment: An empirical investigation', IEEE Transactions on Engineering Management 53(1), 27-47. http://dx.doi.org/10.1109/TEM.2005. 861804

Chen, D.Q., Mocker, M., Preston, D.S. \& Teubner, A., 2010, 'Information systems strategy: Reconceptualization, measurement, and implications', MIS Quarterly 34(2), 233-259.

Chi, L., Jones, K.G., Lederer, A.L., Li, P., Newkirk, H.E. \& Sethi, V., 2005, 'Environmental assessment in strategic information systems planning', International Journal of Information Management 25(3), 253-269. http://dx.doi.org/10.1016/j. ijinfomgt.2004.12.004

Cohen, J.F., 2008, 'Contextual determinants and performance implications of information systems strategy planning within South African firms', Information \& Management, 45(8), 547-555. http://dx.doi.org/10.1016/j.im.2008.09.001

Cohen, J.F. \& Toleman, M., 2006, 'The IS-business relationship and its implications fo performance: An empirical study of South African and Australian organisations' International Journal of Information Management 26, 457-468. http://dx.doi. org/10.1016/j.ijinfomgt.2006.06.002

Cordoba, J.R., 2009, 'Critical reflection in planning information systems: A contribution from critical systems thinking', Information Systems Journal 19(2), 123-147. http://dx.doi.org/10.1111/j.1365-2575.2007.00284.x

Grover, V. \& Segars, A.H., 2005, 'An empirical evaluation of stages of strategic information systems planning: Patterns of process design and effectiveness', Information \& Management 42, 761-779. http://dx.doi.org/10.1016/j.im.2004. 08.002

Hayward, J., 2013, 'Vision and strategic information systems planning in the UK HE Sector', Proceedings of the UK Academy for Information Systems Conference 2013, Paper 13, viewed from http://aisel.aisnet.org/ukais2013/13
Karanja, E. \& Patel, S.C., 2012, 'A review of research trends in strategic information systems planning', International Journal of Business Information Systems 10(2), 151-177. http://dx.doi.org/10.1504/IJBIS.2012.047145

Karpovsky, A. \& Galliers, R.D., 2015, 'Aligning in practice: From current cases to a new agenda', Journal of Information Technology 30, 136-160. http://dx.doi. org/10.1057/jit.2014.34

Kearns, G.S. \& Lederer, A.L., 2003, 'A resource-based view of IT strategic alignment: How knowledge sharing creates competitive advantage', Decision Sciences 34(1), 1-29. http://dx.doi.org/10.1111/1540-5915.02289

Kearns, G.S. \& Sabherwal, R., 2006, 'Strategic alignment between business and information technology: A knowledge-based view of behaviours, outcomes, and consequences', Journal of Management Information Systems 23(3), 129-162. http://dx.doi.org/10.2753/MIS0742-1222230306

Kearns, G.S. \& Sabherwal, R., 2007, 'Antecedents and consequences of information systems planning integration', IEEE Transactions on Engineering Management 54(4), 628-643. http://dx.doi.org/10.1109/TEM.2007.906848

Lederer, A.L. \& Salmela, H., 1996, 'Toward a theory of strategic information systems planning', Journal of Strategic Information Systems 5(3), 237-253. http://dx.doi. org/10.1016/S0963-8687(96)80005-9

Leonard, J. \& Seddon, P., 2012, 'A meta-model of alignment', Communications of the Association for Information Systems 31(11), 230-259.

Luftman, J., Zadeh, H.S., Derksen, B., Santana, M., Rigoni, E.H. \& Huang, Z.D., 2013, 'Key information technology and management issues 2012-2013: An international study', Journal of Information Technology 28(4), 354-366. http:// dx.doi.org/10.1057/jit.2013.22

Mirchandani, D.A. \& Lederer, A.L., 2014, 'Autonomy and procedural justice in strategic systems planning', Information Systems Journal 24(1), 29-59. http://dx.doi. org/10.1111/j.1365-2575.2012.00419.x systems planning under environmental uncertainty', Information \& Management 43(4), 481-501. http://dx.doi.org/10.1016/j.im.2005.12.001

Osman, E., El Beltagi, I.M. \& Hardaker, G., 2013, 'The impact of leadership orientation on strategic information systems planning processes, with an application to Libyan organizations', Information Technology for Development November, 1-27. http:// dx.doi.org/10.1080/02681102.2013.856283

Pai, J.-C., 2005, 'An empirical study of the relationship between knowledge sharing and IS/IT strategic planning (ISSP)', Management Decision 44(1), 105-122. http:// dx.doi.org/10.1108/00251740610641490

Peppard, J., Galliers, R.D. \& Thorogood, A., 2014, 'Information systems strategy as practice: Micro strategy and strategizing for IS', Journal of Strategic Information Systems 23(1), 1-10. http://dx.doi.org/10.1016/j.jsis.2014.01.002

Premkumar, G. \& King, W.R., 1994, 'Organisational characteristics and information systems planning: An empirical study', Information Systems Research 5, 75-109. http://dx.doi.org/10.1287/isre.5.2.75

Preston, D.M. \& Karahanna, E., 2009, 'Antecedents of IS strategic alignment: A nomological network', Information Systems Research 20(2), 159-179. http:// dx.doi.org/10.1287/isre.1070.0159

Ranganathan, C. \& Sethi, V., 2002, 'Rationality in strategic information technology decisions: The impact of shared domain knowledge and IT unit structure', Decision Sciences 33(1), 59-86. http://dx.doi.org/10.1111/j.1540-5915.2002. tb01636.x

Reich, B.H. \& Benbasat, I., 1996, 'Measuring the linkage between business and information technology objectives', MIS Quarterly 20, 453-468. http://dx.doi. org $/ 10.2307 / 249542$

Reich, B.H. \& Benbasat, I., 2000, 'Factors that influence the social dimension of alignment between business and IT objectives', MIS Quarterly 24(1), 81-113. http://dx.doi.org/10.2307/3250980

Schlosser, F., Wagner, H.T. \& Coltman, T., 2012, 'Reconsidering the dimensions of business-IT alignment', Proceedings of the 45th Hawaii International Conference on System Science, 5053-5061. http://dx.doi.org/10.1109/hicss.2012.497

Segars, A. \& Grover, V., 1999, 'Profiles of strategic information systems planning', Information Systems Research 10(3), 199-232. http://dx.doi.org/10.1287/ isre.10.3.199

Silvius, A.J., 2013, Business and IT alignment in context, PhD thesis, Utrecht University, The Netherlands.

Silvius, A.J. \& Stoop, J., 2013, 'The relationship between the process of strategic information systems planning and its success: An explorative study', Proceedings of the 46th Hawaii International Conference on Systems Sciences, 4495-4501. http://dx.doi.org/10.1109/hicss.2013.536

Tan, F.B. \& Gallupe, B., 2006, 'Aligning business and information systems thinking: A cognitive approach', IEEE Transactions on Engineering Management 53(2), 223-237. http://dx.doi.org/10.1109/TEM.2006.872243

Tan, M. \& Teo, T.S.H, 2000, 'Factors influencing the adoption of internet banking', Journal of the Association of Information Systems 1(5), 1-44.

Teo, T. \& King, W., 1997, 'Integration between business planning and information systems planning: An evolutionary contingency perspective', Journal of Management Information Systems 14(1), 185-214.

Teubner, R.A., 2013, 'Information systems strategy', Business \& Information Systems Engineering 5(4), 243-257. http://dx.doi.org/10.1007/s12599-013-0279-z

Yang, J., Pita, Z. \& Singh, M., 2014, 'Measurement of determinants for enhancing strategic information systems planning (SISP) success and dynamic capabilities strategic information systems planning (SISP) success and dynamic capabilities
in South Korea', Proceedings of the 25th Australasian Conference on Information Systems, 8-10 December, Auckland, New Zealand. 


\section{Appendix}

APPENDIX 1: Item measures.

\begin{tabular}{|c|c|c|}
\hline Item & Variable & Source \\
\hline \multicolumn{3}{|c|}{ Shared domain knowledge measure } \\
\hline \multicolumn{3}{|c|}{ Business knowledge } \\
\hline SDK1 & Business executives recognised the potential of IS as a competitive weapon. & Ranganathan and Sethi (2002) \\
\hline SDK2 & Business executives recognised IS as a tool to increase productivity. & Ranganathan and Sethi (2002) \\
\hline SDK3 & Business executives were highly knowledgeable about the firm's information technology assets and opportunities. & Kearns and Sabherwa (2007) \\
\hline SDK4 & $\begin{array}{l}\text { Business executives agreed that information technology could have important intangible benefits that should be } \\
\text { funded. }\end{array}$ & Kearns and Sabherwal (2007) \\
\hline SDK5 & IS executives were highly knowledgeable about business operations of the firm. & Ranganathan and Sethi (2002) \\
\hline SDK6 & IS executives were highly knowledgeable about business strategies of the firm. & Ranganathan and Sethi (2002) \\
\hline
\end{tabular}

SISP rationality measure

Comprehensiveness

COMP1

COMP2

COMP3

COMP4

COMP5

Formalisation

FORM1

FORM2

FORM3

FORM4

FORM5

SISP adaptation measure

Participation

PART1

PART2

PART3

PART4

PART5

Frequency

FREQ1

FREQ2

FREQ3

FREQ4

FREQ5

BP-ISP integration measure

Al

SI

RI

FI

PI
Before a decision was made, each possible course of action was thoroughly evaluated.

The company attempted to determine optimal courses of action from identified alternatives.

There was little trial-and-error in the SISP process.

Decisions were delayed until they were sure that all alternatives were evaluated.

Policies and procedures greatly influenced the process of SISP within the firm.

Formalised planning techniques in the SISP process were utilised.*

The process for strategic planning was very structured.

Written guidelines to structure strategic IS planning existed in the organisation.*

The process and outputs of strategic IS planning were formally documented.
The company attempted to be exhaustive in gathering information relevant for SISP.

Segars and Grover (1999)

Segars and Grover (1999)

Segars and Grover (1999)

Segars and Grover (1999)

Segars and Grover (1999)

Segars and Grover (1999)

Segars and Grover (1999)

Segars and Grover (1999)

Segars and Grover (1999)

Segars and Grover (1999)

Segars and Grover (1999)

Segars and Grover (1999)

Segars and Grover (1999)

Segars and Grover (1999)

Segars and Grover (1999)

Segars and Grover (1999)

Segars and Grover (1999)

Segars and Grover (1999)

Segars and Grover (1999)

Segars and Grover (1999)

Formal planning for information systems was undertaken as the need arose.

Face-to-face meetings to discuss strategic planning issues were frequently scheduled.

Teo and King (1997)

Administrative integration: In this type of integration, there is a weak relationship between business planning (BP) and information systems planning (ISP). Generally there is little significant effort to use information technology (e.g. computers, telecommunications) to support business plans.

Sequential integration: In this type of integration, a sequential relationship exists between business planning (BP) and information systems planning (ISP). BP provides direction for ISP. ISP primarily focuses on providing support for business plans.

Reciprocal integration: In this type of integration, there is a reciprocal and interdependent relationship between business planning (BP) and information systems planning (ISP). ISP plays both a role in supporting and influencing business plans.

Full integration: In this type of integration, there is little distinction between the business planning (BP) process and the information systems planning (ISP) process. Business and information systems strategies are developed concurrently in the same integrated planning process.

Proactive: IS objectives precede the formulation of business objec
IS is considered significant in changing the basis of competition

IT manager participation in business planning

ISBP1 IS executives regularly attended business meetings.

Teo and King (1997)

Teo and King (1997)

Teo and King (1997)

Reich and Benbasat (2000)

Kearns and Sabherwal (2006) Kearns and Sabherwal (2006) Kearns and Sabherwal (2006)

ISBP3

IS executives participated in setting business goals and strategies.

IS executives were involved early in the meetings for major projects.

Social dimension of alignment measure

Long-term alignment

SOC LT AL1

SOC_LT_AL2

Business and IS executives shared a common vision for the long-term role of IS within the organisation.

Cohen and Toleman (2006)

Cohen and Toleman (2006)

SOC_LT_AL3

Business and IS executives agreed on priorities for the organisational use of IS.

Cohen and Toleman (2006)

*, Dropped items.

Business and IS executives agreed on the key IS management issues affecting the organisation. 
APPENDIX 1 (Continues...): Item measures.

\begin{tabular}{|c|c|c|}
\hline Item & Variable & Source \\
\hline \multicolumn{3}{|c|}{ Social dimension of alignment measure $\dagger$} \\
\hline \multicolumn{3}{|l|}{ Short-term alignment } \\
\hline \multicolumn{3}{|c|}{ IS understands business } \\
\hline SOC_ST_AL_IS_BUS1 & IS executives had a good level of understanding of strategic business plans. & Cohen and Toleman (2006) \\
\hline SOC_ST_AL_IS_BUS2 & IS executives had a good level of understanding of the work environment of the business.* & Cohen and Toleman (2006) \\
\hline \multicolumn{3}{|c|}{ Business understands IS } \\
\hline SOC_ST_AL_BUS_IS1 & Business executives had a good level of understanding of the work environment of the IS function.* & Cohen and Toleman (2006) \\
\hline SOC_ST_AL_IS_BUS2 & Business executives had a good level of understanding of strategic IS plans. & Cohen and Toleman (2006) \\
\hline \multicolumn{3}{|c|}{ Intellectual dimension of alignment } \\
\hline \multicolumn{3}{|c|}{ IS plan-business plan alignment } \\
\hline INT_AL1 & The IS plan reflected the business plan mission. & Kearns and Lederer (2003) \\
\hline INT_AL2 & The IS plan reflected the business plan goals. & Kearns and Lederer (2003) \\
\hline INT_AL3 & The IS plan supported the business strategies. & Kearns and Lederer (2003) \\
\hline INT_AL4 & The IS plan recognised external business environment factors. & Kearns and Lederer (2003) \\
\hline \multicolumn{3}{|c|}{ Business plan-IS plan alignment } \\
\hline INT_AL6 & The business plan referred to the IS plan. & Kearns and Lederer (2003) \\
\hline INT_AL7 & The business plan referred to specific IS applications.* & Kearns and Lederer (2003) \\
\hline INT_AL8 & The business plan referred to specific information technologies.* & Kearns and Lederer (2003) \\
\hline INT_AL9 & The business plan utilised the strategic capability of IS. & Kearns and Lederer (2003) \\
\hline INT_AL10 & The business plan contained reasonable expectations of IS. & Kearns and Lederer (2003) \\
\hline
\end{tabular}

*, Dropped items.

$\dagger$, Data continues from previous column. 
APPENDIX 2: Cronbach's alpha and factor analysis.

\begin{tabular}{|c|c|c|c|c|c|}
\hline Items & ADAPT & RATIONAL & SDK_BUS & ISBP & SDK_IS \\
\hline Cronbach's alpha & 0.88 & 0.91 & 0.84 & 0.94 & 0.91 \\
\hline SDK1 & 0.43 & 0.10 & 0.71 & 0.19 & 0.04 \\
\hline SDK2 & 0.24 & -0.11 & 0.64 & 0.35 & 0.02 \\
\hline SDK3 & 0.11 & 0.25 & 0.70 & 0.27 & 0.23 \\
\hline SDK4 & 0.03 & -0.05 & 0.80 & 0.06 & -0.08 \\
\hline SDK5 & 0.23 & 0.04 & 0.17 & 0.31 & 0.79 \\
\hline SDK6 & 0.26 & 0.10 & 0.04 & 0.20 & 0.79 \\
\hline COMP1 & -0.12 & 0.73 & 0.44 & -0.07 & 0.16 \\
\hline COMP2 & 0.26 & 0.80 & 0.18 & 0.09 & -0.01 \\
\hline COMP3 & 0.35 & 0.68 & 0.15 & 0.00 & 0.20 \\
\hline COMP4 & 0.03 & 0.57 & 0.16 & 0.32 & -0.06 \\
\hline COMP5 & -0.01 & 0.77 & -0.06 & 0.18 & -0.04 \\
\hline FORM1 & -0.02 & 0.79 & -0.08 & 0.15 & -0.07 \\
\hline FORM3 & 0.26 & 0.74 & -0.03 & 0.16 & 0.23 \\
\hline PART1 & 0.62 & 0.19 & 0.24 & 0.43 & 0.24 \\
\hline PART2 & 0.72 & 0.06 & 0.30 & 0.17 & 0.38 \\
\hline PART3 & 0.82 & 0.06 & 0.00 & 0.12 & -0.04 \\
\hline FREQ2 & 0.51 & 0.47 & 0.01 & 0.26 & 0.20 \\
\hline FREQ3 & 0.59 & 0.38 & 0.23 & 0.24 & 0.11 \\
\hline FREQ4 & 0.60 & 0.50 & 0.04 & 0.21 & 0.26 \\
\hline FREQ5 & 0.59 & 0.19 & 0.34 & 0.06 & 0.10 \\
\hline ISBP1 & 0.26 & 0.22 & 0.29 & 0.77 & 0.15 \\
\hline ISBP2 & 0.25 & 0.31 & 0.16 & 0.81 & 0.20 \\
\hline ISBP3 & 0.19 & 0.16 & 0.16 & 0.81 & 0.17 \\
\hline Explained variance & 4.08 & 6.02 & 4.20 & 4.86 & 2.75 \\
\hline Proportional total & 0.11 & 0.16 & 0.11 & 0.13 & 0.07 \\
\hline
\end{tabular}

\begin{tabular}{|c|c|c|c|c|}
\hline Items & INT_ISPBPALIGN & INT_BPISPALIGN & SOC_STALIGN & SOC_LTALIGN \\
\hline Cronbach's alpha & 0.93 & 0.92 & 0.76 & 0.92 \\
\hline SOC_LT_AL1 & 0.20 & 0.36 & 0.45 & 0.54 \\
\hline SOC_LT_AL2 & 0.22 & 0.12 & 0.39 & 0.78 \\
\hline SOC_LT_AL3 & 0.25 & -0.02 & 0.39 & 0.63 \\
\hline SOC_ST_AL_IS_BUS1 & 0.38 & 0.15 & 0.65 & 0.21 \\
\hline SOC_ST_AL_BUS_IS2 & 0.14 & 0.33 & 0.72 & 0.35 \\
\hline INT_AL1 & 0.80 & 0.22 & 0.19 & 0.28 \\
\hline INT_AL2 & 0.78 & 0.27 & 0.21 & 0.24 \\
\hline INT_AL3 & 0.72 & 0.19 & 0.36 & 0.20 \\
\hline INT_AL4 & 0.80 & 0.01 & 0.12 & -0.19 \\
\hline INT_AL5 & 0.85 & 0.15 & 0.04 & 0.14 \\
\hline INT_AL6 & 0.26 & 0.58 & 0.19 & 0.22 \\
\hline INT_AL9 & 0.19 & 0.55 & 0.36 & -0.03 \\
\hline INT_AL10 & 0.32 & 0.54 & 0.32 & 0.07 \\
\hline Explained Variance & 4.36 & 4.20 & 4.86 & 2.42 \\
\hline Proportional total & 0.12 & 0.11 & 0.13 & 0.07 \\
\hline
\end{tabular}

